\title{
Connecting with the user-generated Web: how group identification impacts online information sharing and evaluation
}

\author{
Andrew J. Flanagin $^{\mathrm{a} *}$, Kristin Page Hocevar ${ }^{\mathrm{a}}$ and Siriphan Nancy Samahito ${ }^{\mathrm{b}}$ \\ ${ }^{a}$ Department of Communication, University of California Santa Barbara, 4005 SS\&MS, Santa Barbara, CA \\ 93106, USA; ${ }^{b}$ Lewis PR, San Francisco, CA, USA
}

(Received 5 November 2012; final version received 8 May 2013)

\begin{abstract}
Online information pools, such as user-generated encyclopedias and websites that aggregate users' ratings of various products and experiences, are increasingly popular venues where people seek out and share information. While cues about the identity of information sources may be limited in these venues, they may nonetheless incite a sense of shared group membership and social identity among users. This study applies Social Identity Theory and Self-Categorization Theory to examine the effects of group identification on people's information contribution and evaluation behaviors in online information pools. Experimental results indicate that shared group identification positively influences motivation, which in turn influences contribution to information pools. Additionally, people tend to find information contributed by similar others to be more credible and they are also more likely to indicate that they will act on this information. The implications of these findings on the sustenance of information pools, and for information sharing in the contemporary media environment more broadly, are discussed.
\end{abstract}

Keywords: user-generated content; online information pools; social identity; group identification; motivation; credibility; social media

The capacity of the Web to facilitate information sharing among disaggregated individuals is among its most important features. In recent years, for example, there has been a dramatic rise in user-generated content, where individuals are increasingly responsible not just for consuming, but also for producing, many of the information resources available online (see, e.g. Bruns, 2008; Mathes, 2004; Ochoa \& Duval, 2008). One result of widespread user-generation of content online is the establishment of 'information pools' or online information goods comprising combined inputs that can be accessed by a large number of individuals (Cheshire \& Antin, 2008, 2010). Contemporary examples of information pools include a broad range of resources such as Wikipedia, Yelp, TripAdvisor and a wide array of discussion groups, forums, and online communities. Today, such information pools comprise a substantial portion of the rich information environment available online.

One of the most valuable features of information pools is that they enable widely dispersed and diverse users to seek out and interact with others who are different from the people they may encounter regularly offline. In the process, people often come to view online information

*Corresponding author. Email: flanagin@comm.ucsb.edu 
pools as communities (Cho, Chen, \& Chung, 2010; Kim, Zheng, \& Gupta, 2011), which can incite among users a sense of group identification or shared identity. This sense of shared group membership may help sustain these communities by encouraging users to trust in information sources and their input, and by encouraging them to also contribute information to these pools themselves. Yet, there is also compelling evidence that the bonds of shared group identity may inhibit people's propensity to engage with others who do not share markers of that identity (Fox \& Giles, 1996), thereby decreasing the likelihood of capitalizing on the diversity of users and information available online. Consequently, the same indicators of group identification that might prompt cooperation may also act against open information sharing.

To explore this tension, this study focuses on the role of group identification in information pools. We examine how group identification affects the ways in which information pools are formed and sustained, as well as how information seekers evaluate the information they find in them. To do so, we report the results of an experiment where group identification is manipulated in order to gauge its effects on people's information contribution motivations and behaviors, their perceived credibility of knowledge in online information pools, their likelihood of heeding the advice of others, and their perceptions of the value of their own personal information. These results are then considered in terms of how information pools can either help users engage with information and opinions that are different from their own, or inhibit this diversity by making information sharing more myopic, as people share information with others who are already similar to them.

\section{Group identification and information contribution}

Social Identity Theory (SIT) posits that the identity of an individual is dependent upon group identification (Tajfel \& Turner, 1986; Turner, 1975), and that individuals will identify with and support their social group ('ingroup') over other groups with which they do not identify ('outgroups'). Self-Categorization Theory (SCT; Turner, 1991) further poses that individuals act based on a shared group identity rather than different personal identities. Individuals have many different self-categorizations (or self-concepts), and these identities can vary in different contexts depending on what self-category is salient at any particular time. With regard to information pools, SIT and SCT suggest that people may more readily contribute information under conditions where shared group identification is salient.

Indeed, salient group identity has been found to motivate information contribution in a variety of online contexts. For example, on movie ratings websites people are more likely to rate a movie when it is believed to be valuable to others who like the same movie genres as the rater (Rashid et al., 2006). Similarly, people are more likely to contribute to an online ratings system when their group identification with other contributors is made salient and they are under the impression that their contributions will benefit ingroup members (Ling et al., 2005). Team affiliation is also positively related to the level of contributions to SETI@home, a computing project where participants volunteer their computers' extra processing power (Nov, Anderson, \& Arazy, 2010). Affiliation with a team of other SETI@home users moderates the negative relationship between tenure and contribution, such that for team-affiliated contributors increased tenure is associated with only a minor decline in contribution, whereas this decline in contribution is much steeper for contributors who are not affiliated with a team. Accordingly, research also indicates that arbitrary group affiliations can actually encourage social loafing (i.e. contributing less effort toward a collective task) or free riding on others' information contributions, whereas a group identity that promotes trust and a shared purpose can decrease these behaviors (Cheshire \& Antin, 2010). Consistent with this finding, higher involvement with a blogging community has been shown to increase the amount of contributions to that community (Kim et al., 2011). 
Although some research has used subjects' performance on various tasks as a measure of motivation to test expectations of free riding (e.g. Kerr \& Bruun, 1983), few studies have measured subjects' perceived motivation to contribute information. Yet, many argue that behavior is prefaced by a conscious thought about the behavior (see, e.g. Sorrentino, 1996). Research and theory in social psychology, for instance, indicates that the relationship between stimuli and action may involve an intervening process of conscious thought about the action, such that thought works multiplicatively with underlying sources of motivation to amplify the effects of motivating stimuli (Sorrentino, 1996). In the context of information pools and group identity, this suggests that motivation to contribute information might proceed from group identification and result in actual contributions to the pool. Consistent with the work of Atkinson and Birch (1970), who theorize that conscious thought may partly correlate with action and partly mediate between stimulus and action, this implies the mediating role of motivation between group identity and actions such as contribution to an information pool.

Accordingly, the availability of cues indicating similarity between a user and prior contributors may prompt a sense of collective identity, belonging, or community for the user that triggers salient, shared ingroup identity. For example, a survey of Everything2 users found that participants who feel a sense of belonging to the website community are more likely to indicate that they plan to contribute to the site in the future (Lampe, Walsh, Velasquez, \& Ozkaya, 2010). In turn, shared identity may act as a stimulus to instigate the action of contributing information to an online pool. Thus, a potential information provider will need to give conscious consideration to his or her desire to contribute in order to make a decision about contributing. In this way, the influence of group identification on an information provider's contribution amount may proceed through conscious thought about his or her motivation to contribute to the information pool, as proposed in $\mathrm{H} 1$ and $\mathrm{H} 2$ :

H1: Users with strong (versus weak) group identification will be more motivated to contribute to an online information pool.

$\mathrm{H} 2$ : The stronger their motivation to contribute to an online information pool, the more users will actually contribute to that pool.

\section{Group identification and information evaluation}

While a minority of Internet users contribute the majority of information to online pools (Ochoa \& Duval, 2008), upwards of 75\% of Americans have sought out information from such outlets (Pew Research Center, 2012). To assess the credibility of the contents of information pools, information consumers rely on a number of factors, including indicators that signal the credibility of the message and its source (Metzger, Flanagin, Eyal, Lemus, \& McCann, 2003), which have both been shown to affect credibility judgments in meaningful ways (Walthen \& Burkell, 2002). Source information, in particular, is critical to credibility because it is the primary basis upon which credibility judgments rest (Sundar, 2008).

Yet, scholars note that digital media tools sometimes lack standard authority indicators such as author identity or reputation (Danielson, 2005; Fritch \& Cromwell, 2002), and therefore source information is often unavailable, masked, or missing online. In other cases, source information is provided, but hard to interpret, such as when information is co-produced, re-purposed from one site, channel, or application to another or when information aggregators display information from multiple sources in a centralized location that may itself be perceived as the source. These issues have prompted concerns about the credibility of online information because they create uncertainty regarding who is responsible for information and, thus, whether it should be believed (Rieh \& Danielson, 2007). 
This lack of traditional source indicators suggests that oftentimes users must rely on other strategies to assess information sources online. The use of heuristic strategies, for example, suggests that users attend to readily available, though perhaps less concrete or more cursory, cues that might indicate source credibility online, such as web page design elements, popularity, or surface indicators of knowledge and expertise (Flanagin \& Metzger, 2007; Fogg et al., 2003; Metzger, Flanagin, \& Medders, 2010).

A potential key heuristic cue indicating source credibility in information pools is the extent to which an information consumer shares a common group identity with information providers. Under conditions where relevant group information is shared online, such as with ratings sites and blogs that include biographical material about information providers, such cues may allow information consumers to assess the extent to which they share group identification with the information source. Because shared group identification may incite in information seekers a sense of trust of information contributors, this, in turn, may influence how they evaluate the information they find. Indeed, information originating from a source substantially similar to an individual is more likely to be perceived by that individual as credible, as is information consistent with the information searcher's existing beliefs and values (Metzger et al., 2010). This suggests the centrality of source similarity in strategies used to assess online information credibility. Therefore, particularly when traditional source information is limited, it follows that credibility assessments will be higher when information consumers and providers share group affiliation, as posed in H3:

H3: Users with strong (versus weak) group identification will perceive information in an online information pool to be more credible.

The perceived similarity between information source and seeker can increase the degree to which information is persuasive (Brock, 1965). For example, people are more likely to be persuaded by a message originating from ingroup members than one coming from outgroup members (McGarty, Haslam, Hutchinson, \& Turner, 1994) and perceiving the source of information to be credible can predict an information seeker's tendency to follow advice offered by the source (Briggs, Burford, De Angeli, \& Lynch, 2002). Moreover, research in online health advice indicates that people tend to seek out and trust information that appears to originate from those who are like-minded (Sillence, Briggs, Harris, \& Fishwick, 2007).

The effects of SCT have also been found in online environments, where people tend to like and prefer to interact with those who are demographically similar to them (Cosley, Ludford, \& Terveen, 2003). Ingroup preferences hold true even in conditions when the persuasive message comes from a 'virtual human' or a computer-created digital representation of a human in a virtual world (Guadagno, Blascovich, Bailenson, \& McCall, 2007). Despite knowing that the message was coming from a human-like computer algorithm, participants tended to be more persuaded by a virtual human that seemed to be the same gender as the participant than they were by virtual humans who did not appear to be the same gender. Perceived shared group identification, then, may be positively related to the likelihood that people plan to heed advice that they find online, as stated in $\mathrm{H} 4$ :

H4: Users with strong (versus weak) group identification will be more likely to accept advice found in an online information pool.

\section{Group identification and information value}

Consistent with SIT and SCT, potential content contributors may be more motivated and likely to contribute useful material to information pools when they appear to be populated and used by similar others. SCT, for instance, argues that when people define themselves based upon a 
shared social group or category, they become 'depersonalized', perceiving increased intragroup similarities and acting based upon a shared identity and conception of self (Turner, 1991; Turner $\&$ Haslam, 2001). Because people see themselves as representatives of a social group, they may begin to believe that things that are of value to them would also be of value to other members of the group. Indeed, shared group membership has been found to be positively associated with knowledge self-efficacy or the degree to which a person believes his or her knowledge will be useful to others (Cho et al., 2010). In this way, shared social identity may positively influence how an information provider assesses the value of his or her information to others, as posed in $\mathrm{H} 5$ :

H5: Users with strong (versus weak) group identification will rate their shared information to be more valuable to others.

\section{Method}

Hypotheses were tested by an experiment in which subjects viewed a fictitious website in the general theme of the 'Rate My Professor' website (http://www.ratemyprofessors.com) and responded to a series of questions after exposure to the site. Subjects were randomly assigned to either a high or low group-identification condition and were able to contribute information to the site as well as view and evaluate information contributed to the site by others.

\section{Sample and procedure}

A total of 105 undergraduate college student subjects $(N=105)$, consisting of $19 \%(n=20)$ males and $81 \%(n=85)$ females (with ages ranging from 18 to $22[M=19.54, \mathrm{SD}=1.07])$, participated in the study. Subjects were randomly assigned to an experimental condition of high or low group identification. No sex or age differences between conditions were found.

Prior to exposure to the stimulus website, all participants were asked to complete a Web-based questionnaire in which they indicated their class standing, major/minor, sex, student type (e.g. undergraduate, transfer, exchange) and expected year of graduation as well as their past, present, and future course enrollment plans (i.e. which classes they have taken, are taking, and would like to take). Subjects were then informed that they were going to participate in a study aimed to assess a spin-off of the well-known 'Rate My Professor' course-rating website that had recently been started by a group of students at their university, specifically for students only at their university. In reality, the site was constructed as a stimulus for this study by a computer programmer employed by the researchers.

Participants were next directed to the stimulus course-rating website, where they first provided ratings information for courses they had already taken (as indicated in their pre-stimulus questionnaire) and were next presented with ratings information ostensibly offered by past users of the site for the course they had indicated they were most interested in taking. The website displayed a number of ratings and qualitative comments about that course, which subjects were led to believe were contributed by fellow students. In reality, this information did not vary by condition or participant, though it was rendered to appear specific to the course in question.

Group identification was manipulated with the aid of participants' responses to their prestimulus questionnaire, and by instructions immediately preceding their use of the stimulus website. In the high group-identification condition, the course ratings and comments to which subjects were exposed were portrayed as originating from fellow students from the same or substantially similar class standing, university, major, sex, student type, and graduation year, by the presence of these indicators that were displayed alongside the course rating and assessment information appearing on the page. In addition to the presence of this information, subjects were also 
informed prior to visiting the page that several students similar to them would benefit from the information they provided. In the low group-identification condition, the information presented on the website was displayed as having come from students who differed substantially from the subject demographically (i.e. the class standing, university, major, sex, student type, and graduation year appearing alongside the course rating and assessment information was substantially dissimilar to subjects' own information), and subjects were merely informed that their contributions to the site would be viewed by 'several different people' (rather than by students who were similar to them).

Following submission of their ratings and comment contributions to the site (which constituted subjects' information contribution, as detailed below), a Web-based questionnaire was administered to perform manipulation checks and to assess the study's remaining dependent variables: motivation to contribute information, perceived credibility, advice acceptance, and perceived information value.

\section{Measures}

All items were measured on a 7 -point scale, where $1=$ strongly disagree and $7=$ strongly agree. Group identification was assessed by a modified version of group-identification items from Hogg and Hains (1996). After removing four items and adjusting wording to better fit the present study, six items were used to measure participants' perceptions of similarity, fit, identification, attraction, and belonging to the online group from which advice was received (Cronbach's $\alpha=0.88$ ).

Motivation to contribute information was measured by an original scale composed of items assessing the degree to which participants felt motivated to provide good information. The measure was composed of two items, 'I was highly motivated to provide information to others on [the site]' and 'I really wanted to provide others with the very best information I could when using [the site]' (Cronbach's $\alpha=0.80$ ).

Credibility was assessed with five items measuring participants' perceptions of the believability, accuracy, trustworthiness, bias, and completeness of the information provided about the course they indicated they were interested in taking (Flanagin \& Metzger, 2007). Bias scores were reversecoded. The mean value of the five items constituted the final message credibility measure (Cronbach's $\alpha=0.84$ ). Advice acceptance was measured by an original scale composed of items assessing the degree to which participants indicated they would heed the online advice they received. Sample items include 'I am very likely to follow the advice of others I saw on the site' and 'I will use the advice I saw on the site to help me select classes I sign up for in the future' (Cronbach's $\alpha=0.84$ ).

Information Value was measured with a scale composed of three items to determine the degree to which participants felt their information was valuable to others. Sample items include 'My information contribution is especially valuable to other students' and 'The information I contributed is important to other students' (Cronbach's $\alpha=0.80$ ). Depth of processing, as described in the analysis section, was a covariate measured by an original scale composed of four items. Sample items include 'While looking at the information today, I dedicated my attention completely to the task' and 'I carefully read the information I saw today on the [website's] pages' (Cronbachs's $\alpha=0.83$ ).

Information contribution was measured by the length of the comments, in number of words, input into the ratings system.

\section{Results}

\section{Manipulation check}

An independent samples $t$-test was used to assess the effectiveness of the manipulation of group identification. Results indicated that group identification differed as intended, with those receiving 
high group-identification cues exhibiting greater scores $(M=4.99, \mathrm{SD}=.98)$ on group identification than those subjected to low group-identification cues $(M=4.32, \mathrm{SD}=.98 ; t(2,103)=3.50$, $p<.001)$.

\section{Hypothesis testing}

H1 posed that users with strong (versus weak) group identification will be more motivated to contribute to an online information pool and $\mathrm{H} 2$ posed that motivation would in turn be positively related to the actual amount of information contributed. The Baron and Kenny (1986) causal steps approach and a bootstrap resample analysis were used to examine the indirect effect of group identification on information contribution via motivation. The causal steps strategy was chosen due to its widespread recognition as a method that clearly and logically tests the causal process of mediation as well as its ability to test continuous data and thus retain more power over other methods (Pedhazur, 1997; Preacher \& Hayes, 2008b). Using the Baron and Kenny causal steps approach, group identification does not directly predict information contribution, as expected by an indirect (as opposed to mediated) relationship, $b=.20, t=1.02, p=.31$ (see Preacher $\&$ Hayes, 2008b, for a discussion of significant and non-significant total effects). However, group identification significantly predicts motivation to contribute information, $b=.55, t=2.37, p=.02$. Motivation to contribute significantly predicts actual contribution levels, $b=8.74, t=3.58, \mathrm{p}=.001$. Motivation to contribute also significantly predicts contribution levels when controlling for group identification, $b=.27, t=3.40, p=.001$.

While the causal steps strategy's simplicity renders it the most prevalent mediation test, it has been criticized for its low power as well as increased likelihood of Type 1 error (Preacher \& Hayes, 2008b). Many scholars now recommend bootstrapping over other mediation tests, including the causal steps strategy, partial correlation, Sobel test, and differences in coefficients, because bootstrap resample analysis has higher power than other approaches while still limiting Type 1 error (see, e.g. MacKinnon, Lockwood, Hoffman, West, \& Sheets, 2002; MacKinnon, Lockwood, \& Williams, 2004; Preacher \& Hayes, 2004, 2008a, 2008b). Bootstrap resample analysis tests indirect effects through intervening or mediating variables by repeatedly resampling with replacement. Because distribution is often non-normal, particularly in smaller samples, percentile bootstrap confidence intervals (CIs) improve upon techniques where sampling distribution normality is assumed because CIs can be asymmetrical (Preacher \& Hayes, 2008b). Thus, to confirm the results of the causal steps test, a 5000 resample bootstrap analysis was conducted, showing a significant, indirect effect $=-.15,95 \%$ CI $[-.32,-.02]$, indicating a significant indirect effect of group identification on total information contributed via motivation to contribute information. Thus, $\mathrm{H} 1$ and $\mathrm{H} 2$ were supported.

H3, H4, and H5 proposed that group identification would have a positive effect on subjects' perceived credibility of online information, the likelihood of information seekers to accept online advice, and how valuable subjects perceived their own information to be to others, respectively. These hypotheses were tested via a MANCOVA analysis, with perceived credibility, advice acceptance, and information value as the dependent variables, and the experimental condition of group identification as the independent variable. Because subjects' depth of processing could vary by group identification and affect the dependent variables, this variable was statistically controlled in the analysis.

There was a significant multivariate effect for condition (Wilks' $\lambda=.93, F[3,100]=2.64, p=$ .05 , partial $\left.\eta^{2}=.07\right)$. The univariate follow-up tests revealed that the level of perceived credibility $\left(F[1,102]=7.31, p<.01\right.$, partial $\left.\eta^{2}=.07\right)$ in the high group-identification condition $(M=4.70$, $\mathrm{SD}=.89)$ was significantly greater than in the low condition $(M=4.23, \mathrm{SD}=.97)$. Additionally, the level of advice acceptance $\left(F[1,102]=4.71, p<.05\right.$, partial $\left.\eta^{2}=.04\right)$ was significantly greater 
in the high group-identification condition $(M=5.04, \mathrm{SD}=1.12)$ than the low $(M=4.56, \mathrm{SD}=$ $1.23)$. However, the levels of information value did not differ between conditions $(F[1,102]=$ 2.71, $p=.10)$. Thus, H3 and H4 were supported, but H5 was not.

\section{Discussion}

The results of $\mathrm{H} 1$ and $\mathrm{H} 2$ suggest that motivation to contribute to information pools is stimulated by shared group identification, which ultimately results in information contributions. This indirect effect of group identification on contribution supports models where conscious thought works with underlying sources of motivation to amplify the effects of motivating stimuli (Sorrentino, 1996). Consistent with the Theory of Reasoned Action, which posits that attitudes and subjective norms influence behavioral intent, which in turn predicts actual behavior (Fishbein \& Ajzen, 1975), these findings provide an interesting counterpoint to research that indicates a direct effect of group identification on information contribution levels (e.g. Rashid et al., 2006). As Nahapiet and Ghoshal (1998) note, salient group identification can influence an individual's motivation for information exchange. Findings from this study confirm this relation and extend the link from motivation to action as well.

SIT and SCT indicate that salient shared group identity will influence attitudes about a behavior and subjective norms (i.e. normative pressures or the motivations to comply with others' beliefs about a behavior), particularly if the behavior benefits the group. Accordingly, findings showed that potential contributors had more positive attitudes (manifested in the form of increased motivation) about contribution to an online information pool when they experienced shared group identification with others. Similarly, group identification appears to have influenced subjective group norms of information contribution, indirectly through motivation, suggesting that the effects of shared social identity can shape the community by encouraging new information contributors as long as they are substantially similar to prior ones. Moreover, findings demonstrate that the relatively strong effects of group identification posed by SIT and SCT endure even in the context of online venues, where shared social identity is signaled through cues that may be somewhat limited, as compared to the cues available in offline contexts. Future research is necessary to identify the specific conditions required to engage shared group identity online, to determine the characteristics of environments that can provide sufficient cues about the identities of other contributors to motivate action.

Group identification was also found to influence how people evaluate the information they find online. H3 showed that group identification had a significant positive effect on people's evaluations of the credibility of the information they found in the pool. Although the identity of an online information source may often be incomplete, it appears that information seekers are still using the available cues about an information provider to guide their evaluation assessments. H4 showed that group identification had a significant positive effect on the likelihood that information seekers plan to heed the advice that they find online. This, in concert with the results of $\mathrm{H} 3$, suggests that group identification is an important influence on both how people assess information in pools and what they plan to do with that information, implying that shared group identification online may affect individuals' behavior both on- and offline.

The direct link between group identification and behavioral intent demonstrated in $\mathrm{H} 4$ (in the form of the intent to use the advice gleaned from the information pool) extends the work of Cho et al. (2010), who found an indirect link between group membership and intent to contribute information to Wikipedia, through generalized reciprocity. However, because Cho et al. (2010) measured intent to contribute information (as opposed to actual contributions) and the present study measured intent to accept advice (as opposed to measuring if such advice was actually followed), future research should examine actual behaviors more closely, in order to see whether 
people are indeed more likely to heed advice and to change their behavior based on information they receive from those people online with whom they share group identity.

We hypothesized in H5 that as representatives of a shared social group people would believe that others in the group would find their information contributions to be of high value. Yet, in spite of the strong effects of shared group identity demonstrated elsewhere in this study, H5 was not supported. The collective effort model (Karau \& Williams, 1993, 2001), which posits that people will work hard on a group task when they believe that their effort will help them achieve a valued outcome, may shed some light on this. In their meta-analysis of studies that examined social loafing (i.e. exerting less effort on a collective task) in groups, Karau and Williams (1993) found that perceived information uniqueness moderated social loafing, such that uniqueness is motivational when people believe that their contributions will not be redundant with others' information (and will therefore be more instrumental in obtaining a valued outcome). Thus, contrary to what we hypothesized, it appears that high group identification might potentially act to convince information contributors that their knowledge is redundant with others' information. Therefore, potential information contributors may believe that their information is actually less valuable to those with whom they share group identity, rather than more so, because they assume that others like them are likely to already hold the same information.

A specific goal of this study was to assess the degree to which information pools are wellsuited for involving widely dispersed and diverse users to interact via information sharing with people who are different from themselves. On one hand, information pools might extend involvement among a variety of users, each of whom potentially brings different information and value to the overall pool. On the other hand, evidence suggests that because shared group identity may inhibit people's willingness to engage with others who are unlike them, the likelihood of capitalizing on the diversity of users and information available online might be diminished.

Our findings suggest that cues about the identity of contributors to online information pools will encourage more motivation to contribute among, and more contributions from, those who are similar to current information providers than from those who are different from them. Moreover, information seekers who visit these venues will find the information to be more credible if it originates from similar others, and will be more likely to act on this information offline. Thus, our findings suggest the perpetuation of like information being shared, trusted, and perhaps shared again among similar group members, consistent with social researchers who have long hypothesized that people tend to seek out information that is congruent with their preexisting attitudes (Lazarsfeld, Berelson, \& Gaudet, 1944; Sears \& Freedman, 1967), particularly in the contemporary media environment where people enjoy a wide range of choices (Garrett, 2009; Johnson, Bichard, \& Zhang, 2009; Knobloch-Westerwick \& Meng, 2009). Although there are important limits to this logic, for example, the overall effects are mollified by the sheer number of venues and there is prone to be variance by site features, information topic, and individual demographic and attitudinal factors, it does suggest some limitations of user-generated information and online information pools for fostering diverse information environments.

\section{Conclusion}

Information pools comprise a rich online resource that is formed and sustained by information contributors and their inputs. Findings from this study indicate that although cues about the identity of users of information pools or the source(s) of information online are often limited, they may be sufficient to stimulate a feeling of shared or divergent group identification between information consumers and sources. In addition, people tend to be more motivated to contribute information to online pools when they believe that the others who will view and 
benefit from this information are similar to themselves. People also tend to find information contributed by similar others to be more credible and are also more likely to indicate that they will act on this information.

Information pools, then, may actually form and sustain themselves best as communities comprising similar people with similar views. This supports a conceptualization of information pools not only as communities or groups (Cho et al., 2010; Kim et al., 2011) but more specifically as groups of similar users. In this way, information pools to some extent foster the sharing of similar opinions and knowledge much like the information shared between similar group members offline. Thus, sharing and seeking information online may allow us to engage with others who may be widely dispersed and geographically distant, but perhaps still hold perspectives that are somewhat similar to our own.

\section{Notes on contributors}

Andrew J. Flanagin is a professor in the Department of Communication at the University of California at Santa Barbara. His research focuses on the ways in which information and communication technologies structure and extend human interaction, with particular emphasis on the processes of organizing and information evaluation and sharing. [email: flanagin@comm.ucsb.edu]

Kristin Page Hocevar is a graduate student in the Department of Communication at the University of California at Santa Barbara. Her research interests broadly include knowledge sharing using new communication technologies, with a focus on motivations that influence online information contribution and evaluation. [email: kphocevar@umail.ucsb.edu]

Siriphan Nancy Samahito is a marketing professional specializing in brand development and search engine marketing. She is currently a Marketing Executive at Lewis PR, a global public relations and digital communications agency in San Francisco, CA. [email: nancy.samahito@lewispr.com]

\section{References}

Atkinson, J. W., \& Birch, D. (1970). The dynamics of action. Oxford: John Wiley.

Baron, R. M., \& Kenny, D. A. (1986). The moderator-mediator variable distinction in social psychological research: Conceptual, strategic, and statistical considerations. Journal of Personality and Social Psychology, 51, 1173-1182.

Briggs, P., Burford, B., De Angeli, A., \& Lynch, P. (2002). Trust in online advice. Social Science Computer Review, 20(3), 321-332.

Brock, T. C. (1965). Communicator-recipient similarity and decision change. Journal of Personality and Social Psychology, 1(6), 650-654.

Bruns, A. (2008). Blogs, Wikipedia, second life and beyond - from production to produsage. New York, NY: Peter Lang.

Cheshire, C., \& Antin, J. (2008). The social psychological effects of feedback on the production of Internet information pools. Journal of Computer-Mediated Communication, 13, 705-727.

Cheshire, C., \& Antin, J. (2010). None of us is as lazy as all of us. Information, Communication \& Society, 13(4), 537-555.

Cho, H., Chen, M., \& Chung, S. (2010). Testing an integrative theoretical model of knowledge-sharing behavior in the context of Wikipedia. Journal of the American Society for Information Science and Technology, 61(6), 1198-1212.

Cosley, D., Ludford, P., \& Terveen, L. (2003, November 9-12). Studying the effect of similarity in online task-focused interactions. Proceedings of the 2003 ACM SIGGROUP conference, Sanibel Island, Florida.

Danielson, D. R. (2005). Web credibility. In C. Ghaoui (Ed.), Encyclopedia of human-computer interaction (pp. 713-721). Hersey, PA: Idea Group.

Fishbein, M., \& Ajzen, I. (1975). Belief, attitude, intention and behavior: An introduction to theory and research reading. Reading, MA: Addison-Wesley.

Flanagin, A. J., \& Metzger, M. J. (2007). The role of site features, user attributes, and information verification behaviors on the perceived credibility of web-based information. New Media \& Society, 9(2), 319-342. 
Fogg, B. J., Soohoo, C., Danielson, D. R., Marable, L., Stanford, J., \& Trauber, E. R. (2003). How do users evaluate the credibility of Web sites? A study with over 2500 participants. Proceedings of the 2003 conference on Designing for User Experiences, San Francisco, CA, pp. 1-15.

Fox, S. A., \& Giles, H. (1996). 'Let the wheelchair through!': An intergroup approach to interability communication. In W. P. Robinson (Ed.), Social groups and identities: Developing the legacy of Henri Tajfel (pp. 215-248). Oxford: Butterworth Heinemann.

Fritch, J. W., \& Cromwell, R. L. (2002). Delving deeper into evaluation: Exploring cognitive authority on the Internet. Reference Services Review, 30(3), 242-254.

Garrett, R. K. (2009). Echo chambers online? Politically motivated selective exposure among Internet news users. Journal of Computer-Mediated Communication, 14, 265-285.

Guadagno, R. E., Blascovich, J., Bailenson, J., \& McCall, C. (2007). Virtual humans and persuasion: The effects of agency and behavioral realism. Media Psychology, 10, 1-22.

Hogg, M. A., \& Hains, S. C. (1996). Intergroup relations and group solidarity: Effects of group identification and social beliefs on depersonalized attraction. Journal of Personality and Social Psychology, 70(2), 295-309.

Johnson, T. J., Bichard, S. L., \& Zhang, W. (2009). Communication communities or 'cyberghettos?': A path analysis model examining factors that explain selective exposure to blogs. Journal of ComputerMediated Communication, 15(1), 60-82.

Karau, S. J., \& Williams, K. D. (1993). Social loafing: A meta-analytic review and theoretical integration. Journal of Personality and Social Psychology, 65(4), 681-706.

Karau, S. J., \& Williams, K. D. (2001). Understanding individual motivation in groups: The collective effort model. In M. E. Turner (Ed.), Groups at work: Theory and research (pp. 113-141). Mahwah, NJ: Lawrence Erlbaum Associates.

Kerr, N. L., \& Bruun, S. E. (1983). Dispensability of member effort and group motivation losses: Free-rider effects. Journal of Personality and Social Psychology, 44(1), 78-94.

Kim, H., Zheng, J. R., \& Gupta, S. (2011). Examining knowledge contribution from the perspective of an online identity in blogging communities. Computers in Human Behavior, 27, 1760-1770.

Knobloch-Westerwick, S., \& Meng, J. (2009). Looking the other way: Selective exposure to attitude-consistent and counterattitudinal political information. Communication Research, 36(3), 426-448.

Lampe, C., Walsh, R., Velasquez, A., \& Ozkaya, E. (2010). Motivations to participate in online communities. Proceedings of CHI 2010, Atlanta, GA.

Lazarsfeld, P. F., Berelson, B., \& Gaudet, H. (1944). The people's choice. New York, NY: Columbia Press.

Ling, K., Beenen, G., Wang, X., Chang, K., Frankowski, D., Resnick, P., \& Kraut, R. E. (2005). Using social psychology to motivate contributions to online communities. Journal of Computer Mediated Communication, 10(4). Retrieved from http://jcmc.indiana.edu/vol10/issue4/ling.html

Mackinnon, D. P., Lockwood, C. M., Hoffman, J. M., West, S. G., \& Sheets, V. (2002). A comparison of methods to test mediation and other intervening variable effects. Psychological Methods, 7, 83-104.

Mackinnon, D. P., Lockwood, C. M., \& Williams, J. (2004). Confidence limits for the indirect effect: Distribution of the product and resampling methods. Multivariate Behavioral Research, 39, 99-128.

Mathes, A. (2004). Folksonomies - cooperative classification and communication through shared metadata, Computer Mediated Communication, LIS590CMC (Doctoral seminar). Graduate School of Library and Information Science, University of Illinois, Urbana-Champaign.

McGarty, C., Haslam, S. A., Hutchinson, K. J., \& Turner, J. C. (1994). The effects of salient group memberships on persuasion. Small Group Research, 25(2), 267-293.

Metzger, M. J., Flanagin, A. J., Eyal, K., Lemus, D. R., \& McCann, R. (2003). Credibility in the 21 st century: Integrating perspectives on source, message, and media credibility in the contemporary media environment. In P. Kalbfleisch (Ed.), Communication yearbook 27 (pp. 293-335). Mahwah, NJ: Lawrence Erlbaum.

Metzger, M. J., Flanagin, A. J., \& Medders, R. (2010). Social and heuristic approaches to credibility evaluation online. Journal of Communication, 60(3), 413-439.

Nahapiet, J., \& Ghoshal, S. (1998). Social capital, intellectual capital, and the organizational advantage. Academy of Management Review, 23(2), 242-266.

Nov, O., Anderson, D., \& Arazy, O. (2010, April 26-30). Volunteer computing: A model of the factors determining contribution to community-based scientific research. Proceedings of the 19th international conference on World Wide Web (WWW' '10), Raleigh, NC, pp. 741-750.

Ochoa, X., \& Duval, E. (2008, April 22). Quantitative analysis of user-generated content on the web. Proceedings of the first international workshop on Understanding Web Evolution, Beijing, pp. 19-26.

Pedhazur, E. J. (1997). Multiple regression in behavioral research. Fort Worth, TX: Harcourt Brace College. 
Pew Research Center. (2012). What Internet users do online: Trend data (adults). Retrieved from http:// pewinternet.org/Trend-Data-\%28Adults\%29/Online-Activites-Total.aspx

Preacher, K. J., \& Hayes, A. F. (2004). SPSS and SAS procedures for estimating indirect effects in simple mediation models. Behavior Research Models, Instruments, \& Computers, 36(4), 717-731.

Preacher, K. J., \& Hayes, A. F. (2008a). Asymptotic and resampling strategies for assessing and comparing indirect effects in multiple mediator models. Behavior Research Methods, 40(3), 879-891.

Preacher, K. J., \& Hayes, A. F. (2008b). Contemporary approaches to assessing mediation in communication research. In A. F. Hayes, M. D. Slater, \& L. B. Snyder (Eds.), The Sage sourcebook of advanced data analysis methods for communication research (pp. 13-54). Thousand Oaks, CA: Sage.

Rashid, A. M., Ling, K., Tassone, R. D., Resnick, P., Kraut, R., \& Riedl, J. (2006, April 22-28). Motivating participation by displaying the value of contribution. Proceedings of the SIGCHI conference on Human Factors in computing systems (CHI '06), Montreal.

Rieh, S. Y., \& Danielson, D. R. (2007). Credibility: A multidisciplinary framework. In B. Cronin (Ed.), Annual review of information science and technology (Vol. 41, pp. 307-364). Medford, NJ: Information Today.

Sears, D. O., \& Freedman, J. L. (1967). Selective exposure to information: A critical review. The Public Opinion Quarterly, 31(2), 194-213.

Sillence, E., Briggs, P., Harris, P. R., \& Fishwick, L. (2007). How do patients evaluate and make use of online health information? Social Science \& Medicine, 64, 1853-1862.

Sorrentino, R. M. (1996). The role of conscious thought in a theory of motivation and cognition: The uncertainty orientation paradigm. In P. M. Gollwitzer \& J. A. Bargh (Eds.), The psychology of action: Linking cognition and motivation to behavior (pp. 619-644). New York, NY: Guilford Press.

Sundar, S. S. (2008). The MAIN model: A heuristic approach to understanding technology effects on credibility. In M. Metzger \& A. Flanagin (Ed.), Digital media, youth, and credibility (pp. 73-100). Cambridge, MA: MIT Press.

Tajfel, H., \& Turner, J. C. (1986). The social identity theory of intergroup behavior. In S. Worchel \& W. G. Austin (Eds.), Psychology of intergroup relations (pp. 2-24). Chicago, IL: Nelson-Hall.

Turner, J. C. (1975). Social comparison and social identity: Some prospects for intergroup behavior. European Journal of Social Psychology, 5(1), 5-34.

Turner, J. C. (1991). Social influence. Milton Keynes: Open University Press.

Turner, J. C., \& Haslam, S. A. (2001). Social identity, organizations, and leadership. In M. E. Turner (Ed.), Groups at work: Theory and research (pp. 25-65). Mahwah, NJ: Lawrence Erlbaum Associates.

Walthen, C. N., \& Burkell, J. (2002). Believe it or not: Factors influencing credibility on the web. Journal of the American Society for Information Science and Technology, 53(2), 134-144. 